\title{
Hyperinsulinaemia in youth is a predictor of Type 2 (non-insulin-dependent) diabetes mellitus
}

\author{
P. Z. Zimmet, V.R. Collins, G. K. Dowse and L. T. Knight \\ International Diabetes Institute, Caulfield South, Victoria, Australia
}

Summary. This study aimed to compare plasma insulin concentrations across the age-range from childhood to old age in the populations of Nauru and Tuvalu, and to assess their relationship to the incidence of impaired glucose tolerance and diabetes in young Nauruans. The studies, performed in 1975 and 1976, found that Nauru had a higher prevalence of Type 2 (non-insulin-dependent) diabetes mellitus than Tuvalu. Both studies included subjects of $8-29$ years of age ( $n=320$ in Nauru, $n=318$ in Tuvalu) and on these subjects glucose tolerance status, body mass index and fasting and $2-\mathrm{h}$ (post $75 \mathrm{~g}$ glucose load) plasma insulin concentrations were determined. In Nauru, follow-up surveys in 1982 and 1987 included many of the subjects first seen in 1975/1976, allowing the incidence and natural history of glucose intolerance to be studied. Within the group of subjects with normal glucose tolerance, there was no effect of age on plasma insulin distributions in either population. However, in both populations, $8-19$ year old subjects with normal glucose tolerance had higher body mass index-adjusted geometric mean fasting and 2-h insulin concentrations than older age-groups ( $p<0.001$ for fasting insulin). Body mass index-adjusted geometric mean 2-h plasma insulin was higher in subjects with abnormal glucose tolerance relative to those with normal glucose tolerance in both populations. In Nauruans, 2-h insulin levels at baseline were predictive of impaired glucose tolerance and Type 2 diabetes in 1982, and fasting and 2-h insulin levels predicted development of Type 2 diabetes in 1987. Hyperinsulinaemia in the presence of normal glucose tolerance is evident in young people in Nauru and Tuvalu, as has been demonstrated in other populations known to have high susceptibility to Type 2 diabetes. Even in youth, elevated fasting and 2 - $h$ insulin concentration is predictive of subsequent deterioration in glucose tolerance.

Key words: Type 2 (non-insulin-dependent) diabetes mellitus, incidence, insulin, youth, Nauru, Tuvalu.
Hyperinsulinaemia can predate the development of Type 2 (non-insulin-dependent) diabetes mellitus by many years, as has been shown in longitudinal studies in a number of ethnic groups including Micronesian Nauruans [1], Japanese [2], American Pima Indians [3], MexicanAmericans [4] and Europids [5]. A possible sequence of events for the development of Type 2 diabetes includes hyperinsulinaemia and/or insulin resistance as the primary event, which leads ultimately to secondary pancreatic Beta-cell exhaustion [6]. This latter event may be due to a molecular defect leading to an abnormality of insulin synthesis or secretion which may be genetically determined, or may result from glucotoxicity $[6,7]$. Currently, there is great interest in the possibility that hyperinsulinaemia may be a useful metabolic marker for the prediction of Type 2 diabetes.

In Europid populations, Type 2 diabetes rarely presents before the 5 th or 6 th decade of life. However, in many newly-industrialized nations, where there has been a dramatic, indeed epidemic, rise in the prevalence and inci- dence of Type 2 diabetes, it is not unusual to see cases presenting in the $3 \mathrm{rd}$ and 4 th decades and, occasionally, in the late teens [8-12]. This is certainly the situation in the American Pima Indians [9] and the Micronesian Nauruans [8], communities where Type 1 (insulin-dependent) diabetes is very rare [13].

As Type 2 diabetes is predominantly an adult disorder, few epidemiological studies have specifically addressed possible antecedent markers in children. However, recent cross-sectional reports from three populations including Papua New Guineans [14], Australian Aborigines [15] and Pima Indians [16] suggest that hyperinsulinaemia is already present in childhood.

Our own studies in Pacific Ocean communities have been mainly directed at adult subjects aged 20 years and over, although children and adolescents were included in earlier studies in Nauru [17] and Tuvalu [18]. This report describes plasma insulin concentrations in young subjects from these populations, and investigates whether hyperinsulinaemia predicts the incidence of Type 2 diabetes 


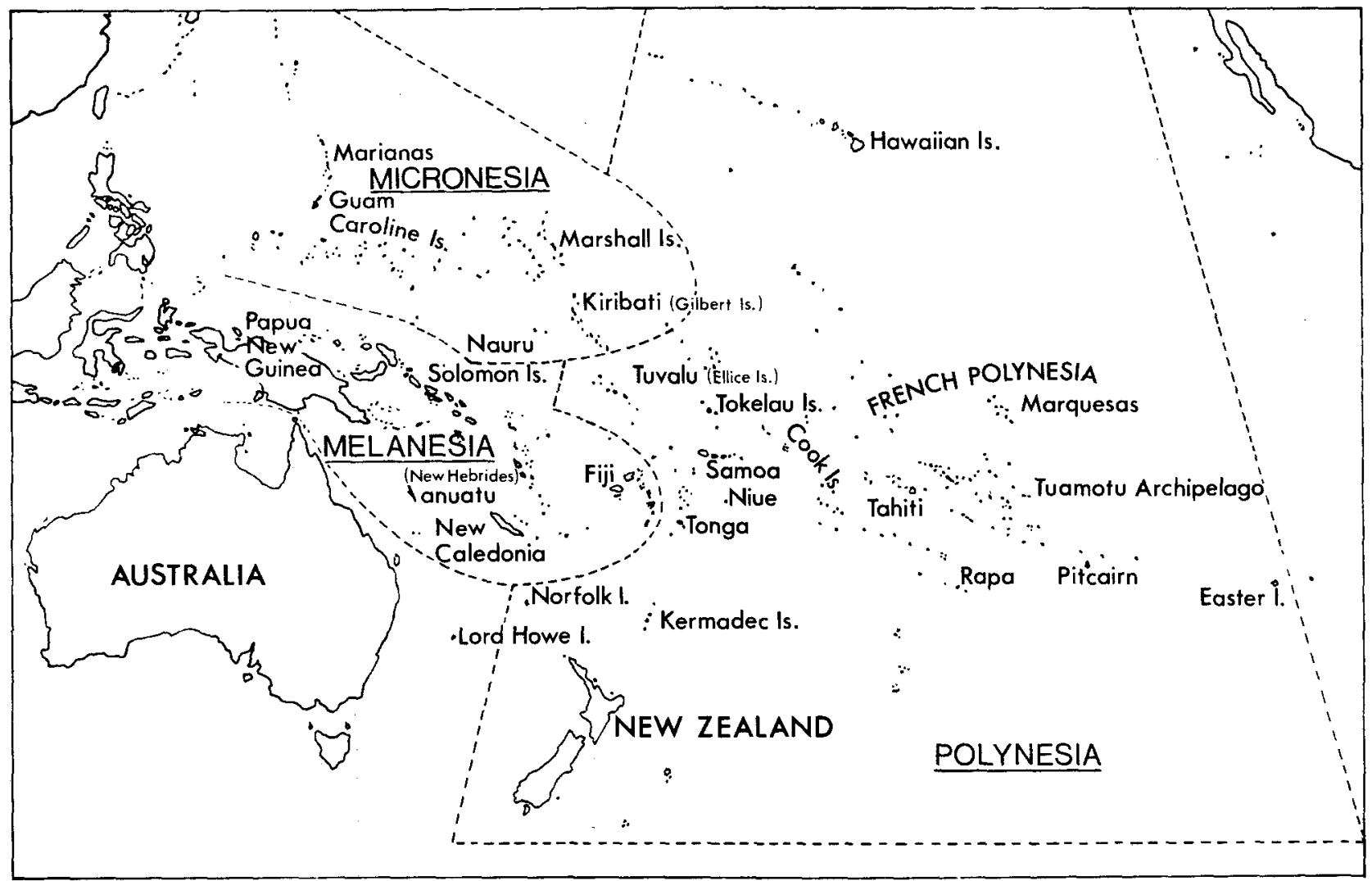

Fig.1. Map of the central Pacific area showing the islands of Nauru and Tuvalu

and impaired glucose tolerance even when detected in youth.

\section{Subjects and methods}

\section{Populations studied}

Nauru is a small (approximately $20 \mathrm{~km}$ circumference) isolated island (Fig. 1) in the Central Pacific Ocean, close to the Equator. The Nauruans have become wealthy due to the mining of rich phosphate deposits on the island, and their lifestyle is characterized by a high consumption of imported processed foods and a sedentary activity habit, resulting in obesity [8]. They also have the second highest prevalence and incidence of Type 2 diabetes yet recorded in the literature $[8,17,19,20]$.

Tuvalu (formerly the Ellice Islands) constitutes a group of eight islands in the central Pacific (Fig. 1). Funafuti, the main island, is situated at longitude $170^{\circ}$ east and latitude $8^{\circ}$ south of the equator and is inhabited by Polynesians believed to have been originally from Samoa. The Funafuti survey was carried out in 1976 [18].

The Nauruans and Funafutians now have a modern lifestyle [17, 18] although the degree of transition from the traditional lifestyle is much greater in the former group due to their relative wealth. Exercise patterns are similar (predominantly sedentary), in adult females of both populations, but the Funafutian men are more physically active than Nauruans. Many Funafutian men were still engaged in heavy physical labour at the time these surveys were performed, whereas the Nauruan males have had predominantly sedentary occupations for at least 20 years.

For the purpose of this paper, analyses were restricted to subjects aged 8-29 years, except where mean insulin values have been compared across all ages. Details of the original sampling procedure, response rates, and survey methodology are reported elsewhere $[8,17$, 18]. Table 1 shows the number of subjects studied by age and glucose tolerance status in Nauru and Tuvalu.

\section{Survey methodology}

All the subjects had participated in diabetes prevalence studies carried out between May 1975 and September 1976 [8, 17, 18]. At the time of testing, none of the subjects were taking insulin, oral hypoglycaemic agents, or any other medication, and none had pre-

Table 1. Prevalence of impaired glucose tolerance (IGT) and Type 2 (non-insulin-dependent) diabetes mellitus across age-groups in Nauru and Tuvalu

\begin{tabular}{llccc}
\hline & $\begin{array}{l}\text { Age group } \\
\text { (years) }\end{array}$ & $\begin{array}{l}\text { Number } \\
\text { of subjects }\end{array}$ & \multicolumn{2}{c}{ Prevalence (\%) } \\
\cline { 5 - 5 } & & & IGT & $\begin{array}{c}\text { Type 2 } \\
\text { diabetes }\end{array}$ \\
\hline Nauru & & 178 & 5.1 & 0.6 \\
& $8-19$ & 164 & 17.1 & 14.0 \\
& $20-29$ & 88 & 25.0 & 28.4 \\
& $30-39$ & 99 & 24.2 & 40.4 \\
& $40-49$ & 30 & 19.7 & 57.6 \\
& $50-59$ & 625 & 17.0 & 22.6 \\
& $60+$ & & & \\
& Total & 198 & 3.5 & 1.0 \\
& $10-19$ & 189 & 4.8 & 0.5 \\
& $20-29$ & 101 & 6.9 & 0.0 \\
& $30-39$ & 104 & 13.5 & 6.7 \\
& $40-49$ & 81 & 19.8 & 7.4 \\
& $50-59$ & 51 & 15.7 & 13.7 \\
& $60+$ & 724 & 8.2 & 2.9 \\
\hline
\end{tabular}

a Tuvalu prevalence standardised to the age structure of the Nauruan population, using the direct method 

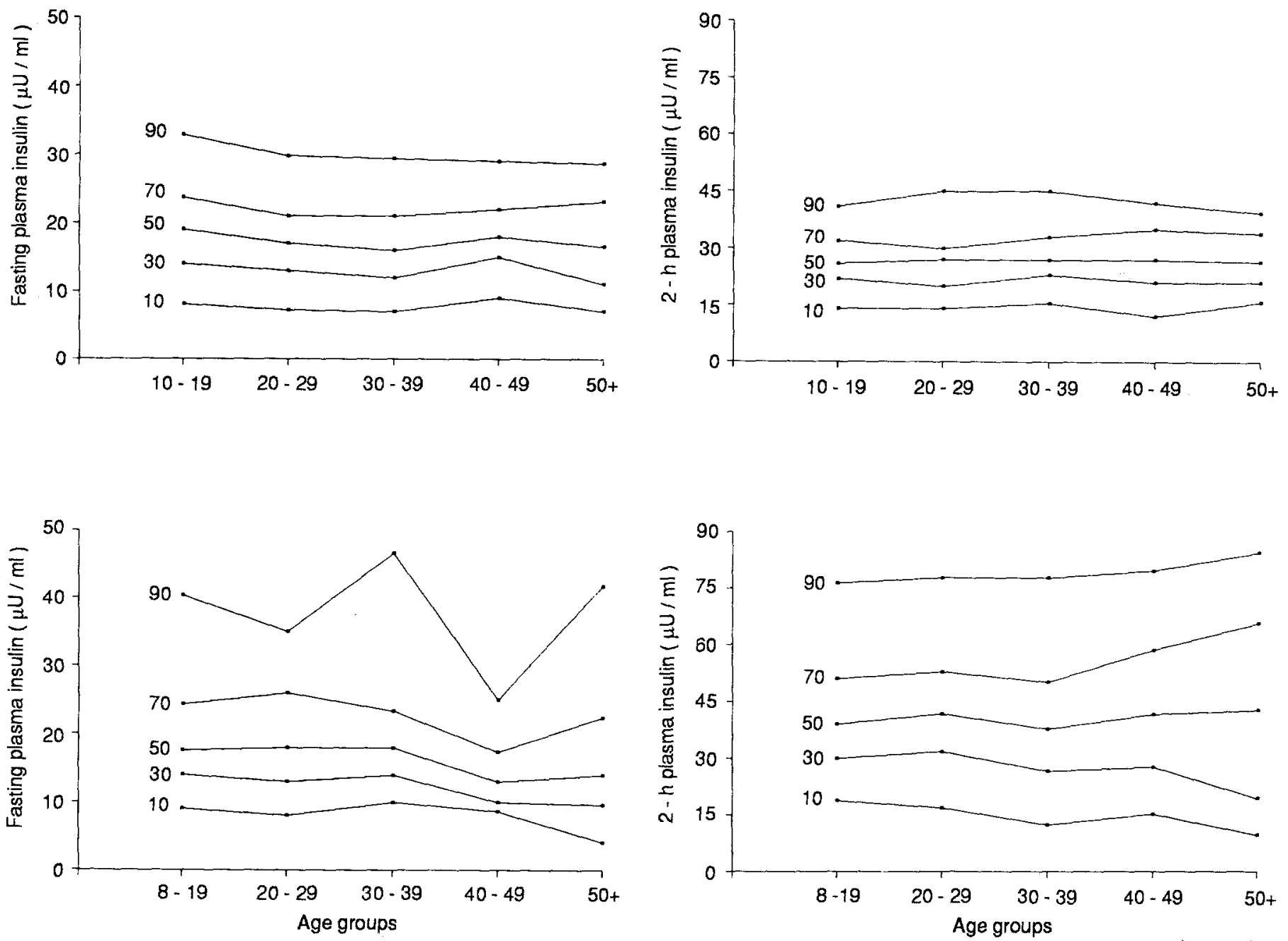

Fig. 2. The 10 th, 30 th, 50 th, 70 th and 90 th percentile values for fasting and 2 -h plasma insulin according to age-group for Nauruans (bottom) and Tuvaluans (top) with normal glucose tolerance

viously received insulin. All subjects were on unrestricted diets (the average Nauruan and Funafutian diet contains over $150 \mathrm{~g}$ of carbohydrate) [21,22]. After an overnight fast, the subjects consumed a 75 -g oral glucose load and venous blood samples were taken fasting and at 2 -h post-glucose load. Samples were centrifuged and plasma glucose concentrations were measured either immediately on-site with a YSI Model 23 AM glucose analyser (Yellow Springs Instrument $\mathrm{Co}$, Yellow Springs, Ohio, USA) or subsequently in Melbourne on frozen specimens using a SMAC 20 autoanalyser (Technicon Instruments Co, Tarrytown, New York, USA). Both machines use a glucose oxidase method. Plasma insulin was determined in duplicate by the radioimmunoassay method of Herbert et al. [23]. In Nauru, the baseline survey was performed in two parts - the first in May 1975 [8] and the second in January 1976 [17]. For the paper the $1975 / 1976$ survey will be referred to as 1976 . Follow-up surveys were performed in 1982 and 1987 [19, 20], allowing study of the incidence and natural history of glucose intolerance.

Body mass index [weight $\left.(\mathrm{kg}) / \mathrm{height}(\mathrm{m})^{2}\right]$ (BMI) was deter mined as an index of obesity. Measures of fat distribution were not included in these early surveys.

\section{Criteria for abnormal glucose tolerance}

The glucose tolerance status of each subject was defined according to the latest recommendations of the World Health Organization

Table 2. Geometric mean fasting and 2-h insulin according to age-group in Nauru (for subjects with normal glucose tolerance in 1976)

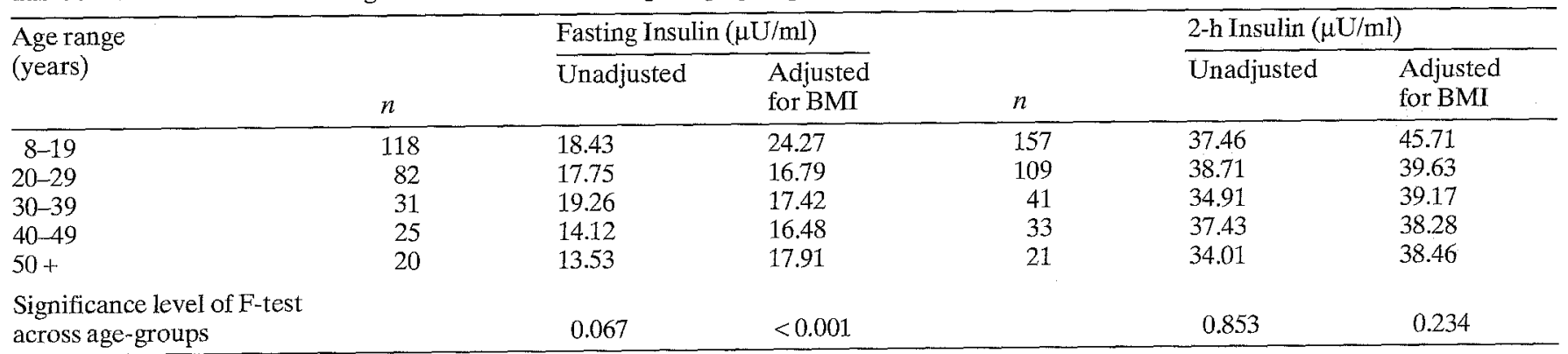


Table 3. Geometric mean fasting and 2 -h insulin according to age group in Tuvalu (for subjects with nonmal glucose tolerance only)

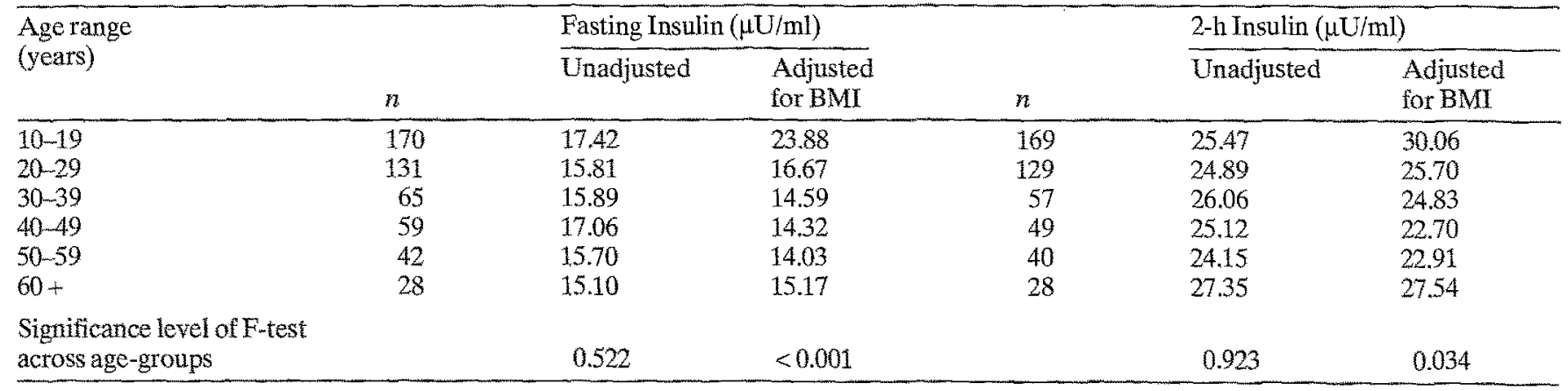

(WHO) Study Group [24]. Venous plasma glucose values $<7.8 \mathrm{mmol} / 2$-h after the $75-\mathrm{g}$ oral glucose load, indicated normal glucose tolerance. Impaired glucose tolerance (IGT) was defined by values $\geq 7.8 \mathrm{mmol} / \mathrm{l}$ but $<11.1 \mathrm{mmol} / \mathrm{and}$ diabetes was diagnosed if the 2 -h plasma glucose value was $\geq 11.1 \mathrm{mmol} / \mathrm{h}$

\section{Statistical analyses}

Analyses were performed using SPSSx software [25]. Logarithms of the plasma insulin values were used to normalise the distribution and to stabilize variance. Means were adjusted for BMI and age by anam lysis of covariance, and differences across groups were assessed by the F-ratio. Geometric mean values have been presented in the tables.

\section{Results}

\section{Cross-sectional data}

The prevalence of IGT and Type 2 diabetes across agegroups is shown in Table 1. It is noteworthy that the prevalence of IGT was already $5.1 \%$ in the $8-19$ year age group in Nauru and that there was high prevalence of both IGT $(17.1 \%)$ and Type 2 diabetes $(14.0 \%)$ in the $20-29$ year category. Impaired glucose tolerance $(3.5 \%)$ and Type 2 diabetes $(1.0 \%)$ were also evident in 10 19 year old subjects in Tuvalu. Age-specific and overall

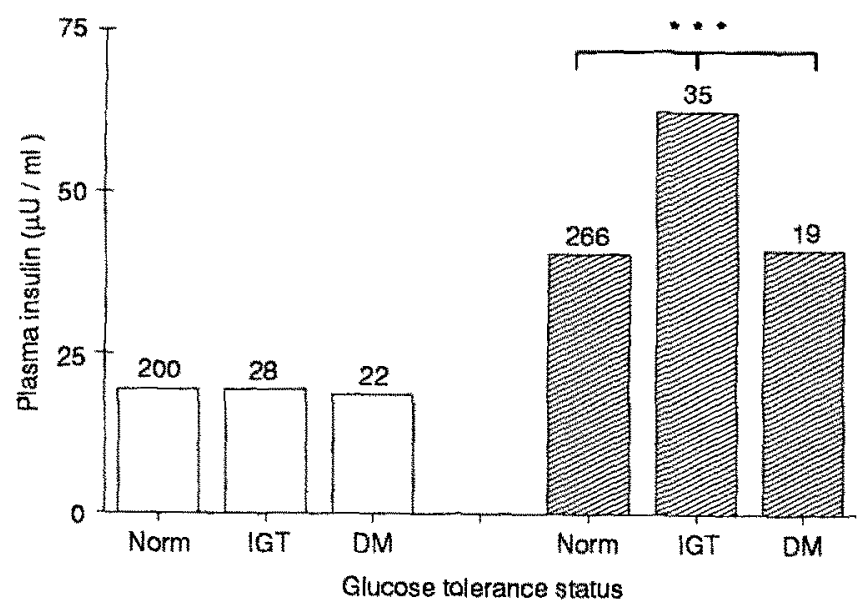

Fig. 3. Age and body mass index-adjusted geometric mean plasma insulin by glucose tolerance status at fasting $\square$ and $2 \mathrm{~h}$ h $\mathrm{h}$ in children and young adults in Nauru (left) and Tuvalu (right). Norm, normal; prevalences of IGT and Type 2 diabetes were considerably higher in the population of Nauru compared with Tuvalu.

The 10th, 30th, 50th, 70th and 90th percentile values for fasting and 2-h insulin are plotted by age-group for Nauruans and Tuvaluans with normal glucose tolerance in Figure 2. These data indicate little relationship between age and the distribution of plasma insulin in the sub-group of individuals with normal glucose tolerance in either population. The large amount of variation in the 90th percentile values for fasting insulin in Nauru probably reflects small numbers in the upper age groups. The insulin distributions are quite different in the two populations. Nauru has a much wider range of insulin values than Tuvalu (especially 2-h insulin) and the median values are higher in Nauru for each age-group.

The unadjusted and BMI-adjusted geometric mean fasting and 2-h plasma insulin concentrations across agegroups are shown in Table 2 for Nauruans with normal glucose tolerance. Due to small numbers, the 50-59 years and $60+$ age-groups have been combined in Nauru. There was significant variation in BMI-adjusted fasting insulin values across age-groups $(p<0.001)$ with highest values in subjects 8-19 years old. For Tuvalu, the trends were essentially the same (Table 3 ) although variation across agegroups was also statistically significant for 2 -h insulin $(p=0.034)$.

The BMI-adjusted geometric mean 2-h plasma insulin plotted by glucose tolerance group in Nauruans aged

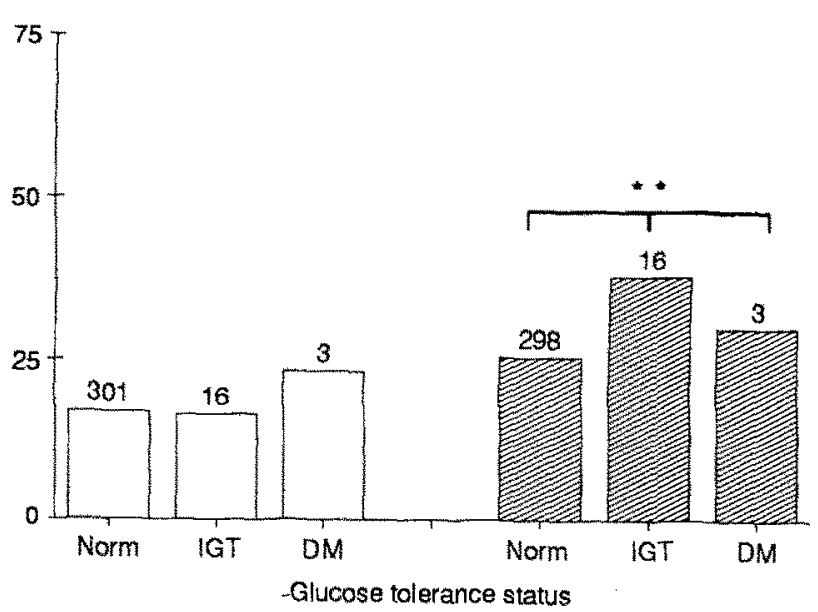

IGT, impaired glucose tolerance; DM, Type 2 (non-insulin-dependent) diabetes mellitus (The numbers above the bars represent subjects in each category.) $* * 0.01 ; * * * p<0.001$ 
Table 4. Geometric mean insulin levels in 1976 for subjects with normal glucose tolerance in 1976 according to glucose tolerance status in 1982 (Nauru)

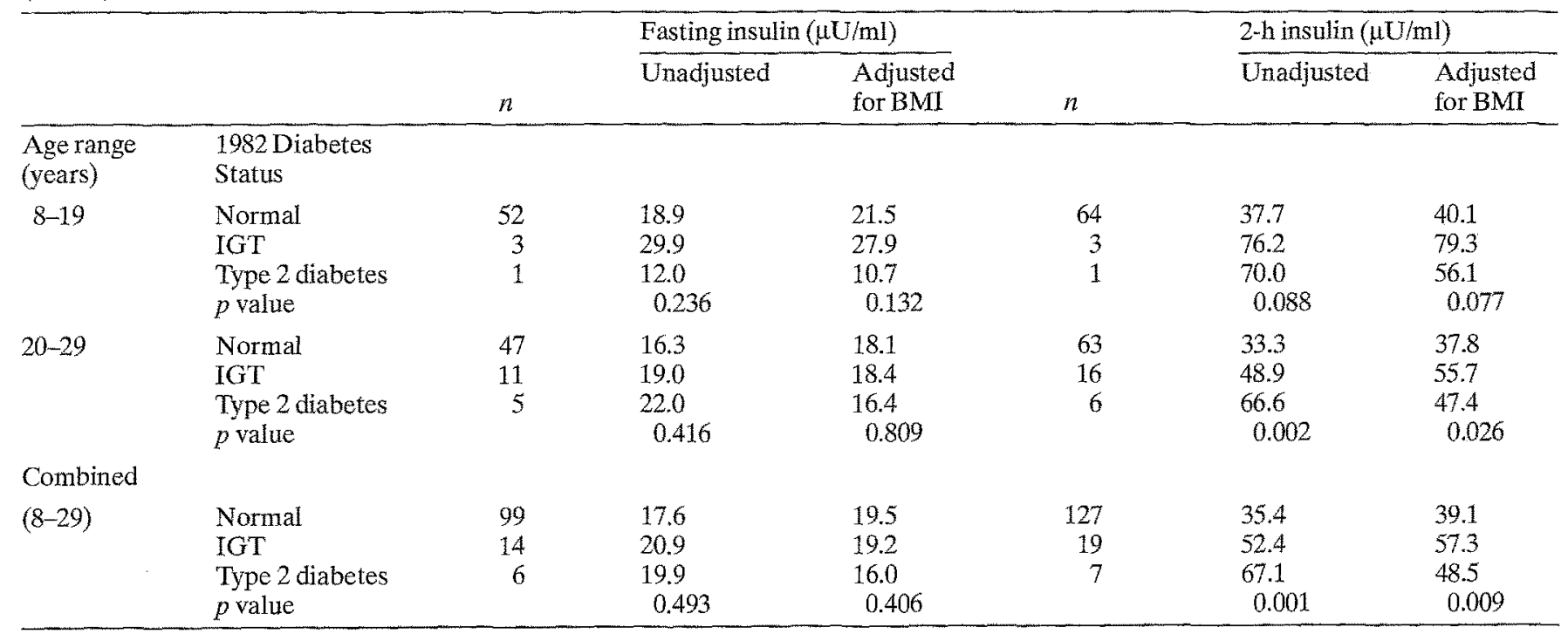

IGT, impaired glucose tolerance

Table 5. Geometric mean insulin levels for subjects with normal glucose tolerance in 1976 according to glucose tolerance status in 1987 (Nauru)

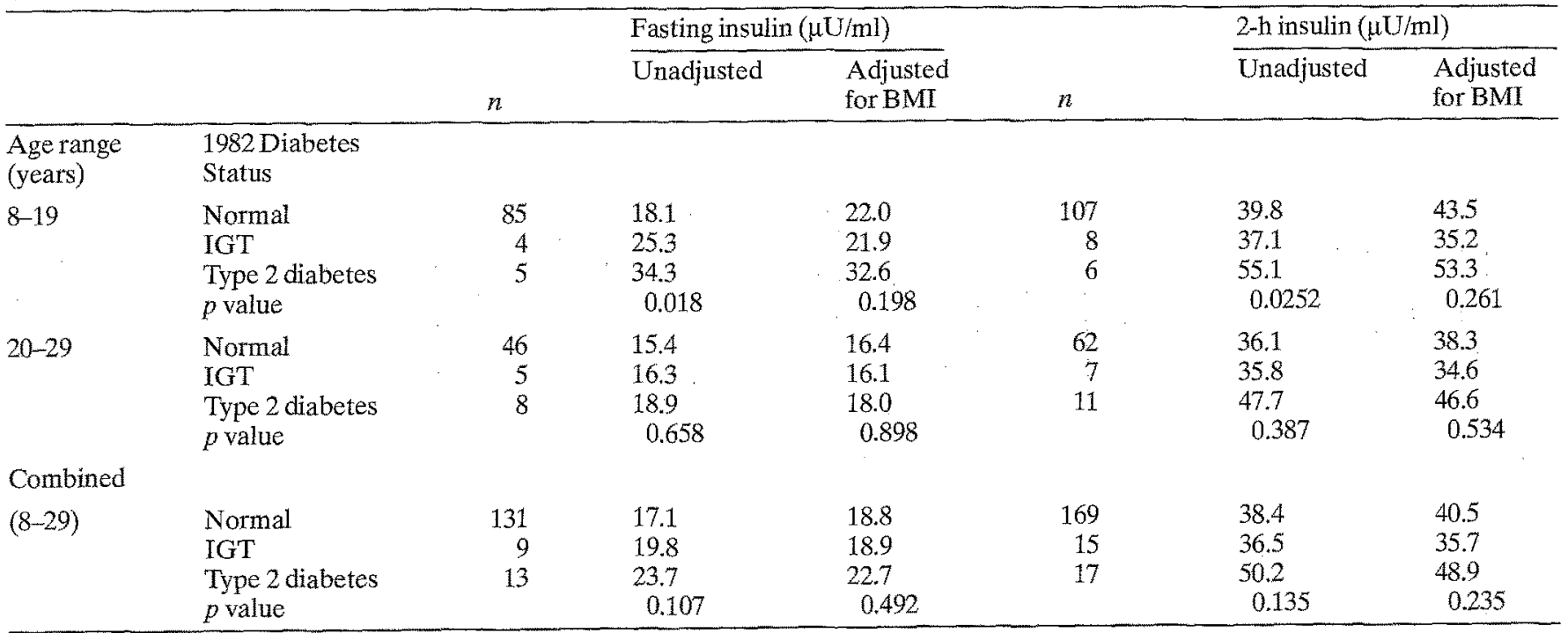

IGT, impaired glucose tolerance

8-29 years showed an inverted "U" shaped pattern with the peak mean plasma insulin concentration in the IGT group (Fig. 3). In Tuvaluans aged 10-29 years, the pattern was similar although there were few subjects in the diabetic group. Geometric mean fasting plasma insulin varied little across glucose tolerance categories except for a non-significant increase amongst diabetic Tuvaluans.

\section{Longitudinaldata-Nauru}

Geometric mean fasting and 2-h plasma insulin concentrations in subjects with normal glucose tolerance in 1976 , adjusted for BMI at baseline, are shown according to glucose tolerance status in 1982 and 1987 in Tables 4 and 5, respectively. Subjects aged both $8-19$ and $20-29$ years who had normal glucose tolerance in 1976 and who subsequently developed IGT at the 1982 follow-up had the highest 2 - $\mathrm{h}$ plasma insulin concentrations at baseline, followed by those who developed Type 2 diabetes (Table 4 ). These values were significantly higher than for subjects whose glucose tolerance remained normal. For the longer period 1976-1987 (Table 5) subjects in either age-group who developed Type 2 diabetes at follow-up had the highest fasting and 2 - $h$ insulin values at baseline although differences were not significant.

In Figure 4, the cumulative incidence of impaired glucose tolerance and Type 2 diabetes for the period 19761982 is shown for the combined age-range 8-29 years, by quartiles of the baseline fasting and $2-\mathrm{h}$ insulin levels. There was a clear linear association between 2 -h insulin (right panel) and the incidence of impaired glucose toler- 

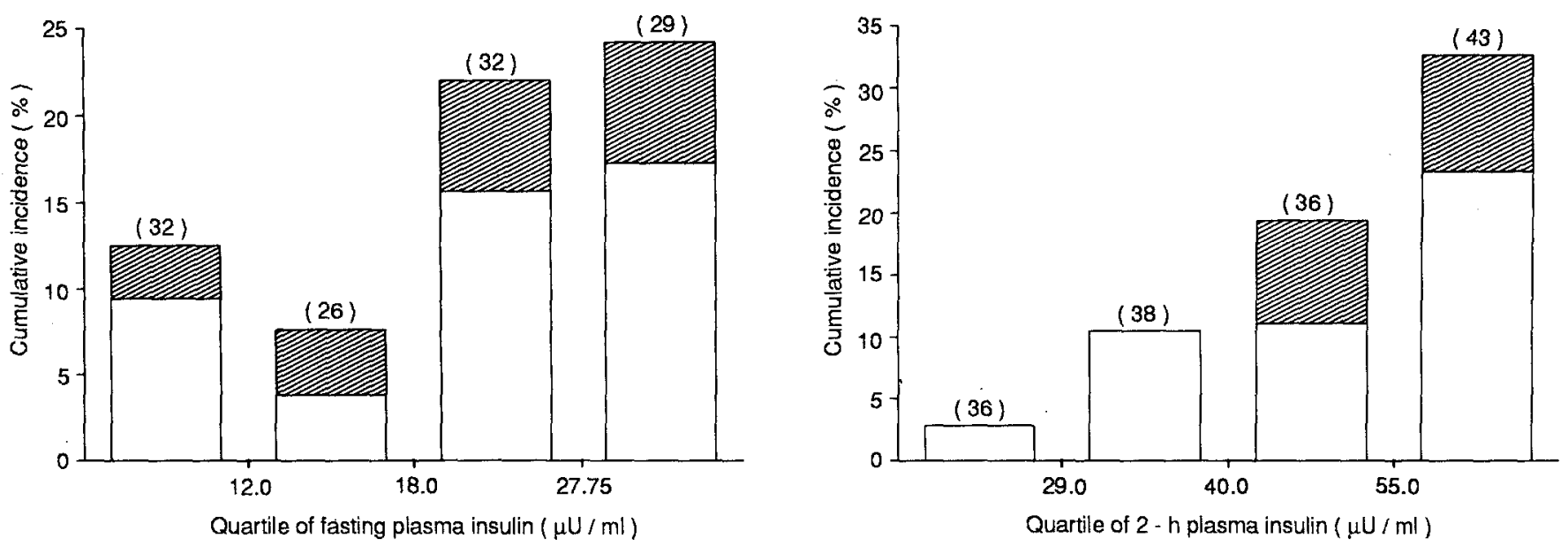

Fig.4. Cumulative incidence of impaired glucose tolerance $\square$ and Type 2 (non-insulin-dependent) diabetes mellitus 恿 for the period 19761982 in Nauruans aged 8-29 years according to quartiles of baseline plasma insulin. (For subjects with normal glucose tolerance in 1976)
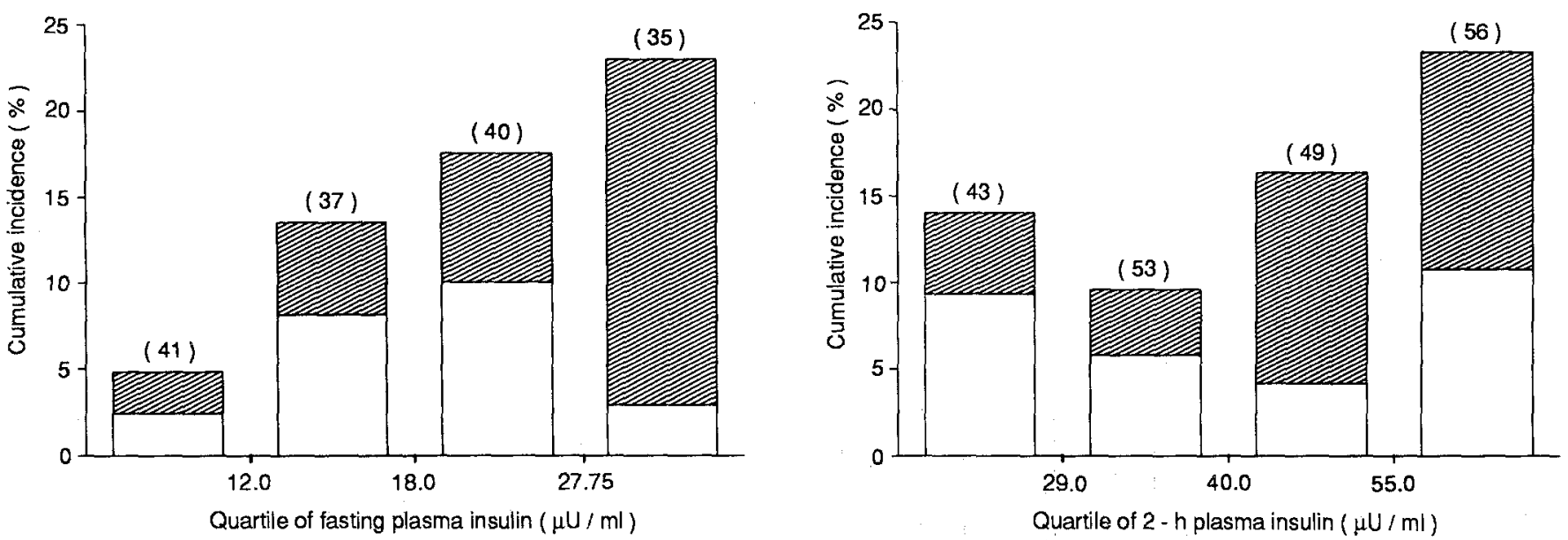

Fig.5. Cumulative incidence of impaired glucose tolerance $\square$ and Type 2 (non-insulin-dependent) diabetes mellitus 1987 in Nauruans aged 8-29 years according to quartiles of baseline plasma insulin. (For subjects with normal glucose tolerance in 1976)

ance and Type 2 diabetes. The cumulative incidence of abnormal glucose tolerance for subjects in the fourth quartile of 2 -h insulin was $32.6 \%$, compared to $2.8 \%$ in the first quartile (relative risk 11.6). For fasting insulin (Fig. 4, left panel) the overall trend was also for increasing incidence of both impaired glucose tolerance and Type 2 diabetes, although the second quartile was aberrant.

For the period 1976-1987 (Fig.5) there was a consistent trend for the cumulative incidence of Type 2 diabetes and combined abnormal glucose tolerance to increase with baseline fasting and, to a lesser extent, 2 - $\mathrm{h}$ insulin quartiles.

\section{Discussion}

These data from Nauru and Tuvalu show that plasma insulin concentrations in children and young adults in these populations are already similar to those of adults, and possibly higher when adjusted for the effect of obesity. Moreover, the shape of the cross-sectional relationship between 2-h plasma insulin and 2-h plasma glucose is similar to that observed in adults, showing the typical inverted "U" or horse-shoe shaped curve [7, 26-28]. Most impor- tantly, hyperinsulinaemia in the presence of normal glucose tolerance, perhaps indicating insulin resistance, may predict the later development of abnormal glucose tolerance in young people.

The prevalence of abnormal glucose tolerance was considerably higher in Nauru than Tuvalu, in all agegroups including young people. This has been noted previously [18] but the data presented here go further to perhaps partly explain this discrepancy. Higher insulin levels (particularly $2-h$ post-load) are evident in Nauru and may contribute to the much higher prevalence of abnormal glucose tolerance [1]. Although Nauruans also have higher mean BMI, when mean insulin levels for the two populations were compared according to categories of BMI, Nauruans still showed significantly higher values for 2-h insulin (data not shown).

The apparent association between 2-h insulin levels and the prevalence of abnormal glucose tolerance was supported by the higher 2-h insulin levels in IGT subjects in both populations. The lower levels in the diabetic group (but still high relative to normal subjects) probably reflect the fact that insulin response declines in overt Type 2 diabetes due to pancreatic Beta-cell decompensation [6]. 
This phenomenon has been observed in adults [7, 26-28] but we have now shown it in young ( $8-29$ year-old) subjects.

In adult Nauruans [1], Pima Indians [3], Mexican-Americans [4] and Europids [5] with normal glucose tolerance, it has been shown that subjects with high plasma insulin levels at baseline are the most likely to develop abnormal glucose tolerance at follow-up. Our data suggest that this may also be true in Nauruan adolescents and young adults. The predictive value of baseline insulin levels (particularly 2-h insulin), however, was more pronounced in the 1976-1982 time period for IGT and Type 2 diabetes than for the longer period 1976-1987, where baseline insulin was predictive of diabetes and not IGT. The inconsistency of the trend for IGT incidence for the 1976-1987 period probably reflects the fact that individuals have already moved through this labile phase of glucose intolerance and on to diabetes over the longer follow-up period. However, total glucose intolerance (IGT and diabetes) is clearly related to baseline insulin (both fasting and 2-h) over this 11-year period.

From these data and from other studies [1,3-5], it is apparent that the presence of hyperinsulinaemia and associated insulin resistance with normal glucose tolerance could be considered an early phase in the development of Type 2 diabetes. Paradoxically, it has been shown that subjects with IGT who have relatively lower (although still high in absolute terms) insulin response at baseline are more likely to develop diabetes than IGT subjects with relatively higher levels $[1,2,29]$. It has been postulated that the former group have already been through the stage of maximal insulin secretion which has then declined due to pancreatic Beta-cell decompensation, and are moving towards the development of overt Type 2 diabetes [6].

Other studies have demonstrated relatively high insulin levels amongst children and young people, in populations at high risk of developing Type 2 diabetes [14-16, 30]. A markedly different profile of glucose tolerance, and in particular of plasma insulin concentrations has been shown between rural and peri-urban Papua New Guinean (Tolai) children, well below the age normally associated with the onset of Type 2 diabetes [14,30]. Relative hyperinsulinaemia was present in the peri-urban children and differences in age or adiposity could not explain the findings. Other cardiovascular risk factors (blood pressure, cholesterol and triglyceride concentrations) were generally similar in the two groups of children. The marked increase in plasma insulin values with increasing plasma glucose in the periurban setting suggested the development of insulin resistance and incipient glucose intolerance [14]. Similar findings have been reported in Australian Aboriginal children [15]. Moreover, lean pre-pubertal Pima Indians, a group disposed to both obesity and Type 2 diabetes later in life, show higher plasma glucose and insulin concentrations than matched Caucasoid children [16]. Thus, hyperinsulinaemia and insulin resistance are present many years before the onset of diabetes in this ethnic group and are predictive of its development [31].

Warram et al. [32] have demonstrated recently that offspring of Type 2 diabetic parents ranging in age from 16 to 60 years have slower glucose removal rates and higher insulin levels (fasting and during the second phase of insulin response to intravenous glucose) than control subjects even after adjustment for differences in obesity. During 13-year follow-up, $16 \%$ of the offspring developed diabetes. The reduced glucose clearance and hyperinsulinaemia could be demonstrated one to two decades before the diabetes was actually diagnosed and our results are consistent with this finding.

The fact that there are identifiable metabolic abnormalities (hyperglycaemia and hyperinsulinaemia) which predict the risk of Type 2 diabetes may have very important implications for its primary prevention. As it appears that the cascade of risk factors for Type 2 diabetes and other associated non-communicable diseases could commence in youth, subjects who have these "metabolic markers", are likely to be at much higher risk than are subjects who have normal glucose and insulin levels and are insulin sensitive [6]. As primary prevention programmes for diabetes may be targetted at the whole community and/or at subjects with highest risk [33], it may be useful to include these young people with high insulin levels in any high-risk strategies. Haffner et al. [4], in their study of Type 2 diabetes incidence in Mexican Americans, found that nearly half of the incident cases developed in a subset of the population who were simultaneously in the highest quartiles of both fasting insulin and glucose concentrations, and suggested that screening for insulin might be a viable preventive measure. However, much more research is necessary to prove that measurement of plasma insulin or Cpeptide levels [34] is cost- and health-effective, before any recommendation for their use in high-risk screening can be seriously entertained. This study does not provide any concrete evidence to indicate that immunoreactive insulin assays are necessarily better than glucose measures or BMI in prediction of future development of glucose intolerance. However, these and other data suggest that the role of insulin in predicting Type 2 diabetes is certainly worthy of further exploration.

There are well-recognized problems with the oral glucose tolerance test (OGTT) and the radioimmunoassay measure of insulin levels, which probably add considerable variability to results and hamper conclusions drawn from population studies of carbohydrate metabolism, such as those reported here. The OGTT has poor reproducibility [35] which can result in misclassification of individuals, and commonly used insulin assays may overestimate circulating insulin levels, particularly amongst diabetic subjects, due to cross-reaction with insulin-like molecules [36]. Although they are generally the most feasible methods for large population studies, they do have limitations when extrapolation to mechanisms of disease pathogenesis is attempted. Nonetheless, such population studies offer perspectives that complement those from clinical and basic science.

There have now been several reports demonstrating relative hyperinsulinaemia in children in populations known to have a high susceptibility to Type 2 diabetes. We reported relatively high insulin levels in children from a rapidly urbanizing previously traditional population in Papua New Guinea [30] and there have been reports from other previously traditional groups, namely Australian Aborigines [15], Pima Indians [16], and now Micronesian Nauruans and Polynesian Tuvaluans. The impact of life- 
style change, and indeed risk of Type 2 diabetes, may be detected in youth, suggesting that population intervention strategies need to be directed across the full age spectrum.

Acknowledgements. Supported by a grant from the National Health and Medical Research Council of Australia, the Nauruan Government and by grant DK-25446 from the National Institute of Diabetes and Digestive and Kidney Diseases. We thank Ms. SFournel and Ms. A Ford for assistance with the manuscript.

\section{References}

1. Sicree RA, Zimmet PZ, King HOM, Coventry JS (1987) Plasma insulin response among Nauruans: prediction of deterioration in glucose tolerance over 6 yrs. Diabetes 36: 179-186

2. Kadowaki T, Miyake Y, Hagura R et al. (1984) Risk factors for worsening to diabetes in subjects with impaired glucose tolerance. Diabetologia 26:44-49

3. Saad MF, Knowler WC, Pettitt DJ, Nelson RG, Charles MA, Bennett PH (1991) A two-step model for development of non-insulin-dependent diabetes. Am J Med 90:229-235

4. Haffner SM, Stern MP, Mitchell BD, Hazuda HP, Patterson JK (1990) Incidence of type II diabetes in Mexican Americans predicted by fasting insulin and glucose levels, obesity and body-fat distribution. Diabetes 39: 283-288

5. Charles MA, Fontbonne A, Thibult N, Warnet J-M, Rosselin GE, Eschwege E (1991) Risk factors for NIDDM in white population. Paris Prospective Study. Diabetes 40: 796-799

6. Zimmet P, Dowse G, Bennett P (1991) Hyperinsulinaemia is a predictor of non-insulin-dependent diabetes mellitus. Diab Metab 17: 101-108

7. De Fronzo RA (1988) The triumvirate: $\beta$-cell, muscle, liver: a collusion responsible for NIDDM. Diabetes 37: 667-687

8. Zimmet P, Taft P, Guinea A, Guthrie W, Thoma K (1977) The high prevalence of diabetes mellitus on a Central Pacific Island. Diabetologia 13: 111-115

9. Savage PG, Bennett PH, Senter RG, Miller M (1979) High prevalence of diabetes in young Pima Indians: evidence of phenotypic variation in a genetically isolated population. Diabetes 28: 937942

10. Zimmet P, Taylor R, Ram P et al. (1983) The prevalence of diabetes and impaired glucose tolerance in the biracial (Melanesian and Indian) population of Fiji: a rural-urban comparison. Am J Epidemiol 118: 673-688

11. Dowse GK, Gareeboo H, Zimmet PZ et al. (1990) The high prevalence of glucose intolerance in Indian, Creole and Chinese Mauritians. Diabetes 39:390-396

12. King H, Taylor R, Koteka G et al. (1986) Glucose tolerance in Polynesia. Population-based surveys in Rarotonga and Niue. Med J Aust 145: 505-510

13. Zimmet $P(1982)$ Type 2 (Non-insulin-dependent) diabetes - an epidemiological overview. Diabetologia 22: 399-411

14. King H, Finch C, Zimmet P, Alpers M (1990) Plasma glucose and insulin responses in young Papua New Guineans (aged 10-19 years). Diabetes Res Clin Practice 10: 153-159

15. White K, Gracey M, Schumacher L, Spargo R, Kretchmer N (1990) Hyperinsulinaemia and impaired glucose tolerance in young Australian Aborigines. Lancet II: 735 (Letter)

16. Pettitt DJ, Moll PP, Kottke BA (1990) Insulin resistance in apparently healthy children. Diabetes 39: 75A (Abstract)

17. Zimmet P, Arblaster M, Thoma K (1978) The effect of westernization on native populations. Studies on a Micronesian community with a high diabetes prevalence. Aust NZ J Med 8: 141146
18. Zimmet P, Seluka A, Collins J, Currie P, Wicking J, DeBoer W (1977) Diabetes mellitus in an urbanized, isolated Polynesian population. The Funafuti Survey. Diabetes 26: 1101-1108

19. Zimmet P, King H, Taylor R et al. (1984) The high prevalence of diabetes mellitus, impaired glucose tolerance and diabetic retinopathy in Nauru - the 1982 survey. Diab Res 1:13-18

20. Dowse GK, Zimmet PZ, Finch CF, Collins V (1991) Decline in incidence of epidemic glucose intolerance in Nauruans: implications for the "thrifty genotype". Am J Epidemiol 133: 1093-1104

21. Ringrose H, Zimmet $P$ (1979) Nutrient intakes in an urbanised Micronesian population with a high diabetes prevalence. Am J Clin Nutr 32: 1334-1341

22. Wicking J, Ringrose H, Whitehouse S, Zimmet P (1981) Nutrient intake in a partly westernized isolated Polynesian population: The Funafuti Survey. Diab Care 4: 92-95

23. Herbert V, Lau KS, Gottlieb CW, Bleicher SJ (1965) Coated charcoal immunoassay of insulin. J Clin Endocrinol Metab 25: 1375-1384

24. WHO Study Group on Diabetes Mellitus (1985) Technical Report Series No 727 WHO Geneva

25. SPSS Inc. (1986) SPSSX user's guide, 2nd edn. McGraw Hill, New York

26. Reaven GM, Miller RG (1979) An attempt to define the nature of chemical diabetes using a multidimensional analysis. Diabetologia 16: 17-24

27. Zimmet P, Whitehouse S, Alford F, Chisholm D (1978) The relationship of insulin response to a glucose stimulus over a wide range of glucose tolerance. Diabetologia 15: 23-27

28. Savage PJ, Dippe SE, Bennett PH et al. (1975) Hyperinsulinemia and hypoinsulinemia. Insulin response to oral carbohydrate over a wide spectrum of glucose tolerance. Diabetes 24:362-368

29. Saad MF, Knowler WC, Pettitt DJ, Nelson RG, Mott DM, Bennett PH (1988) The natural history of impaired glucose tolerance in the Pima Indians. N Engl J Med 319: 1500-1506

30. King H, Alpers M, Finch C, Zimmet P (1989) Future glucose intolerance possibly manifest in youth. Lancet II: 1098-1099

31. Knowler WC, Pettitt DJ, Nelson RG (1989) Ten-year prediction of diabetes by hyperinsulinaemia and parental diabetes in Pima Indian children with normal glucose tolerance. Diabetes 38 [Suppl 2]: $92 \mathrm{~A}$ (Abstract)

32. Warram JH, Martin BC, Krolewski AS, Soeldner JS, Kahn CR (1990) Slow glucose removal rate and hyperinsulinaemia precede the development of type II diabetes in the offspring of diabetic parents. Ann Intern Med 113: 909-915

33. Zimmet $P$ (1988) Primary prevention of diabetes mellitus. Diab Care 11: 258-262

34. Bergstrom RW, Newell-Morris LL, Leonetti DI, Shuman WP, Wahl PA, Fujimoto WY (1990) Association of elevated fasting Cpeptide level and increased intra-abdominal fat distribution with development of NIDDM in Japanese-American men. Diabetes 39: 104-111

35. Eriksson KF, Lindgärde F (1990) Impaired glucose tolerance in a middle-aged male urban population: a new approach for identifying high-risk cases. Diabetologia 33: 526-531

36. Temple RC, Clark P, Schneider A et al. (1990) Radioimmunoassay may overestimate insulin in non-insulin-dependent diabetics. Clin Endocrinol 32: 689-693

Received: 4 November 1991

and in revised form: 21 January 1992

Prof. P.Z.Zimmet

International Diabetes Institute

260 Kooyong Road

Caulfield South, Victoria 3162

Australia 